Article

\title{
Monitoring and Assessing the 2012 Drought in the Great Plains: Analyzing Satellite-Retrieved Solar-Induced Chlorophyll Fluorescence, Drought Indices, and Gross Primary Production
}

\author{
Siheng Wang ${ }^{1,2}$, Changping Huang ${ }^{1, *}$, Lifu Zhang ${ }^{1}$, Yi Lin ${ }^{3}$, Yi Cen ${ }^{1}$ and Taixia $\mathrm{Wu}^{1}$ \\ 1 The State Key Laboratory of Remote Sensing Science, Institute of Remote Sensing and Digital Earth, \\ Chinese Academy of Sciences, Beijing 100101, China; wangsh@radi.ac.cn (S.W.); zhanglf@radi.ac.cn (L.Z.); \\ cenyi@radi.ac.cn (Y.C.); wutx@radi.ac.cn (T.W.) \\ 2 University of Chinese Academy of Sciences, Beijing 100049, China \\ 3 Institute of Remote Sensing and Geographic Information Systems, School of Earth and Space Science, \\ Peking University, Beijing 100871, China; yi.lin@pku.edu.cn \\ * Correspondence: huangcp@radi.ac.cn; Tel.: +86-10-6480-6207
}

Academic Editors: Clement Atzberger and Prasad S. Thenkabail

Received: 19 November 2015; Accepted: 8 January 2016; Published: 27 January 2016

\begin{abstract}
We examined the relationship between satellite measurements of solar-induced chlorophyll fluorescence (SIF) and several meteorological drought indices, including the multi-time-scale standard precipitation index (SPI) and the Palmer drought severity index (PDSI), to evaluate the potential of using SIF to monitor and assess drought. We found significant positive relationships between SIF and drought indices during the growing season (from June to September). SIF was found to be more sensitive to short-term SPIs (one or two months) and less sensitive to long-term SPI (three months) than were the normalized difference vegetation index (NDVI) or the normalized difference water index (NDWI). Significant correlations were found between SIF and PDSI during the growing season for the Great Plains. We found good consistency between SIF and flux-estimated gross primary production (GPP) for the years studied, and synchronous declines of SIF and GPP in an extreme drought year (2012). We used SIF to monitor and assess the drought that occurred in the Great Plains during the summer of 2012, and found that although a meteorological drought was experienced throughout the Great Plains from June to September, the western area experienced more agricultural drought than the eastern area. Meanwhile, SIF declined more significantly than NDVI during the peak growing season. Yet for senescence, during which time the reduction of NDVI still went on, the reduction of SIF was eased. Our work provides an alternative to traditional reflectance-based vegetation or drought indices for monitoring and assessing agricultural drought.
\end{abstract}

Keywords: drought monitoring; solar-induced chlorophyll fluorescence (SIF); drought indices; gross primary production (GPP); Great Plains; hyperspectral remote sensing

\section{Introduction}

Drought-induced reduction of vegetation production threatens both the global ecological balance and food security. The frequency and intensity of drought is increasing under the warmer temperatures resulting from global climate change [1,2]. From 2000 to 2009, global terrestrial net primary production (NPP) declined by $0.55 \mathrm{Pg}$ of carbon because of drought [3]. Hence, the timely monitoring and precise assessment of large-scale drought are important for food security and for understanding vegetation responses to climate change. 
However, drought is very complex and difficult to monitor for two reasons. First, drought is not universally defined. In general, drought can be categorized into meteorological, agricultural, hydrological, and socioeconomic droughts [4], and thus it is hard to define what a "real drought" is. Second, the onset and end point of a drought are indistinct $[5,6]$. Thus, drought is hard to detect in its early stages. Drought indices, such as the Palmer drought severity index (PDSI), which is derived considering both precipitation and temperature [7], and the standard precipitation index (SPI), which is directly calculated from the precipitation over a certain historical period [8,9], have been proposed to simplify the evaluation of drought conditions. Because drought indices are generally calculated from meteorological data, they are able to monitor meteorological drought effectively [10].

However, for terrestrial plants, drought conditions might be affected by non-meteorological factors such as underground water storage and agricultural irrigation with the result that drought indices alone are insufficient to monitor agricultural drought. Remotely-sensed satellite data, providing spatiotemporally continuous observations on vegetation, have been employed to evaluate drought-related vegetation conditions. Reflectance-based vegetation indices (VIs), such as the normalized difference vegetation index (NDVI), can indicate the greenness of terrestrial plants. Other water-sensitive VIs, such as the normalized difference water index (NDWI) [11], or other drought-oriented advanced indices, such as the vegetation condition index (VCI) [12] and the scaled drought condition index (SDCI) [10], are also widely used to study agricultural drought. Because VIs and drought indices are considered as proxies for green biomass and meteorological drought, respectively, and there is a close relationship between vegetation vigor and available soil moisture, especially in unirrigated arid regions, the relationships between vegetation and drought indices directly indicate the response of vegetation to drought and provide a simple method to study meteorologically-induced agricultural drought (e.g., [6,10,13]).

Although previous studies of drought have shown the effectiveness of satellite data, remotely-sensed data have intrinsic limitations for drought monitoring and assessment. One major shortcoming is that the lag in the response of satellite-measured VIs to drought is significant. This is because the spectral characteristics of the vegetation canopy do not change immediately when water stress occurs. For example, the NDVI can still remain high when plants are heavily stressed by short-term drought. Generally, the lag for the NDVI to response precipitation is about one to two months [14,15], while for central North America, this lag is more significant in early summer than in late summer [16]. Despite the improved performance of other VIs (e.g., NDWI, VCI, and SCDI) in monitoring drought, these reflectance-based indices fail to indicate rapid changes in drought stress because they have no direct link to photosynthetic functioning beyond their sensitivity to canopy structure and pigment concentration changes [17]. This makes it difficult to monitor drought in a timely fashion from space when using VIs. Moreover, these satellite products cannot indicate primary production precisely because they are related to potential rather than actual plant photosynthesis. Thus, accurately assessing drought is difficult when these products are used.

Under natural illumination, a part of the unused absorbed photosynthetically active radiation (APAR) is emitted by vegetation as fluorescence, and is referred to as solar-induced chlorophyll fluorescence (SIF) [18]. Recent studies have successfully extracted a global time-series of SIF from satellite observations [18-20]. SIF provides an alternative method for monitoring global vegetation from space, because it is different from traditional reflectance-based vegetation indices. SIF is directly related to the photosynthesis of vegetation and is likely to reflect rapid changes in the water stress of a canopy [21,22]. The relationship between the gross primary production (GPP), APAR, and the light use efficiency (LUE) is as follows:

$$
\begin{gathered}
G P P=A P A R \times L U E \\
S I F=A P A R \times \text { SIFyield },
\end{gathered}
$$

where SIF $_{\text {yield }}$ is the SIF emitted per photon absorbed [23]. According to Equation (2), if the ratio of SIF $_{\text {yield }}$ and LUE remains relatively stable, which has been confirmed under moderate 
illumination [24], SIF will have a linear relationship with GPP [25]. A good consistency between space-borne SIF and flux-measured GPP has been found in different biomes [26], and the SIF-driven NPP model helps to improve the estimation of crop yield [27]. As with the LUE, SIF yield is sensitive to environmental stresses, such as water or heat stress [28,29], so SIF is expected to respond rapidly to agricultural drought and to directly indicate drought-induced reductions of vegetation production. Lee et al. [28] used SIF extracted from the Greenhouse gases Observing Satellite (GOSAT) to evaluate the drought-induced reduction of forest production in Amazonia. Yoshida et al. [25] monitored the Russian drought in 2010 using SIF extracted from the Global Ozone Monitoring Instrument 2 (GOME-2) and found that drought-related declines in LUE and APAR produced losses in SIF and GPP. Sun et al. [30] also reported positive relationships between the SIF and soil water content (SWC) anomalies in Texas and the central Great Plains. However, the relationships between the widely used meteorological drought indices and satellite measurements of SIF have not been examined. Whether the lag between remotely-sensed vegetation parameters and precipitation also holds for SIF has not been confirmed. In addition, the spatiotemporal patterns of drought monitored by drought indices, the NDVI, and SIF have not been compared and discussed.

Our objective in this study was to investigate satellite-measured SIF responses to drought by analyzing the relationship between various meteorological drought indices and SIF, and to examine whether SIF is more sensitive to short-term drought conditions than are reflectance-based VIs. Our study examined the feasibility of directly using satellite-measured SIF to monitor and assess drought. There was an extreme drought in the Great Plains of the USA in 2012, and we compared SIF and ground-based GPP among dry and humid years. We used SIF to monitor the drought during the summer of 2012, and applied a simple model to make an assessment of the drought-induced reduction of GPP throughout the Great Plains. We compared drought patterns derived from meteorological drought indices, SIF, and the NDVI, and discuss our results below.

\section{Data}

\subsection{Study Area}

The Great Plains lie in a climate zone that varies from semi-arid to semi-humid. The main land-cover comprises grassland and cropland, which are sensitive to precipitation and soil moisture. Figure 1 shows the three states used in this study: South Dakota (coded as 39), Nebraska (25), and Kansas (14). Vegetation is continuously distributed in the region, making it appropriate for large-scale drought studies and analyses (e.g., [6,13,16]). The land-cover types were obtained from the MOderate-Resolution Imaging Spectroradiometer (MODIS) land-cover product (MCD12Q1, 2013). Some of the results and analysis in this manuscript are based on the climate division (CD) defined by the National Climate Data Center (NCDC).

\subsection{Drought Indices}

Drought indices have been used as proxies for meteorological drought conditions in studies of drought using remote sensing $[6,10,13,31]$. We used two of the most widely used drought indices, SPI and PDSI. The SPI was calculated by fitting historical precipitation to a Gamma probability distribution function and transforming the Gamma distribution to a normal distribution, with a mean of zero and standard deviation of one [8], which allowed precipitation to be determined over different historical periods. The relationships between various different time scales of SPI and SIF (VIs) indicate the vegetation response to water stress over different historical periods. To compare the sensitivity of SIF and VIs to short-term drought conditions, this study used SPIs based on one month (SPI-1), two months (SPI-2), and three months (SPI-3). The PDSI is based on a simple water balance model that uses an algorithm to compare monthly precipitation to a value required to sustain a climatically appropriate water balance for that month, considering the long-term record for precipitation and temperature. The PDSI can synthetically evaluate the drought condition induced from both water and heat stress. 
The relationship between the PDSI and SIF indicates a change in photosynthesis under temperature and water stress. Monthly SPI and PDSI for the CDs studied from 2008 to 2013 were obtained from the NCDC website: http://gis.ncdc.noaa.gov/.

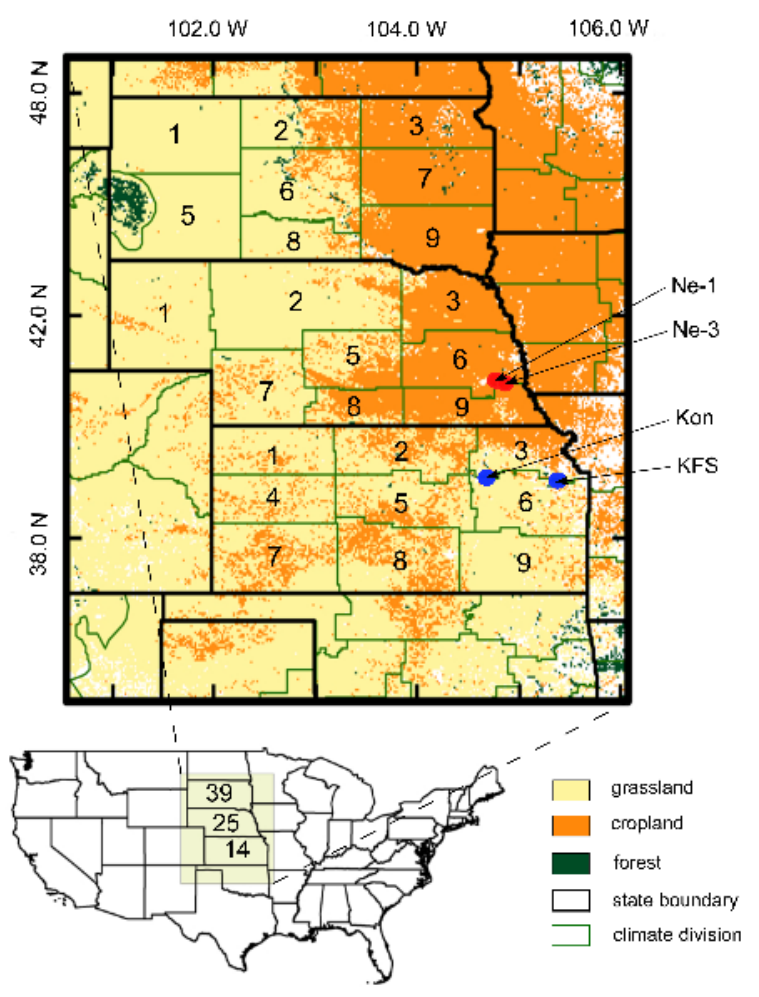

Figure 1. Study area. The numbers in the bottom left subfigure are the codes for the three states, while the numbers (from 1 to 9 ) in the main subfigure are the climate division (CD) codes. The CDs are referred to as the combination of the state code and the CD code hereafter. Ne-1, Ne-3, Kon, and KFS are the names of the flux sites used in this study and the red (cropland) and blue (grassland) circles are their geographic positions.

\subsection{GOME-2 SIF and MODIS VIs}

The Fraunhofer lines, which are the result of absorption in the solar spectra through the atmosphere, allow SIF to be measured from space. Joiner et al. [18] successfully extracted SIF around $740 \mathrm{~nm}$ (SIF-740) using the GOME-2 spectrometer onboard the MetOp-A satellite. The GOME-2 SIF-740 product had similar spatial patterns to the SIF extracted from the GOSAT, but was gridded with a finer spatial resolution, and has been used to estimate global GPP and track phenology $[23,26,27,29,32]$. This study used the monthly averaged gridded SIF-740 data (level 3, v26) from 2008 to 2013, with a spatial resolution of $0.5^{\circ}$ latitude $\times 0.5^{\circ}$ longitude .

In order to make a comparison between the drought sensitivity of SIF and reflectance-based vegetation indices, we took NDVI and NDWI as references. NDVI and NDWI are most widely used as indicators of vegetation vigor, and are calculated as:

$$
N D V I=\frac{\rho_{N I R}-\rho_{R}}{\rho_{N I R}+\rho_{R}}
$$

and

$$
N D W I=\frac{\rho_{N I R}-\rho_{S W I R}}{\rho_{N I R}+\rho_{S W I R}}
$$

where $\rho_{R}, \rho_{\text {NIR }}$ and $\rho_{\text {SWIR }}$ represent the reflectance of the red, near-infrared, and shortwave-infrared bands, respectively. Monthly NDVI and NDWI were obtained from the MODIS Terra product, 
MOD13A3 (website: https:/ /ladsweb.nascom.nasa.gov/). Because Rhee et al. [10] found no significant discrimination among the relationships between drought indices and NDWI using MODIS bands 5, 6, and 7 (as an SWIR band), we calculated NDWI using MODIS bands 2 and 7, as provided by the MOD13A3 product.

\subsection{Flux Tower GPP}

We used the gap-filled 0.5-hourly GPP based on measurements made by an eddy covariance instrument set on a flux tower. The flux data were obtained from the AmeriFlux website: http://ameriflux.lbl.gov/. We used all available flux sites in the focal area, with observations covering the period from 2008 to 2013. Table 1 gives details of the four flux sites and Figure 1 shows their positions.

Table 1. Flux sites used in this study.

\begin{tabular}{cccccc}
\hline Site Name & Longitude & Latitude & Vegetation Type & Time Range & References \\
\hline KFS & -95.19 & 39.06 & grass & $08-13(09$ missing) & {$[33,34]$} \\
Kon & -96.56 & 39.08 & grass & $08-13$ & {$[33,34]$} \\
Ne-1 & -96.29 & 41.10 & irrigated maize & $10-12$ (May to October) & {$[35,36]$} \\
Ne-3 & -96.44 & 41.18 & rain-fed maize & $10-12$ (May to October) & {$[35,36]$} \\
\hline
\end{tabular}

\section{Methodology}

We first examined the response of SIF to drought by analyzing the relationship between SIF and several drought indices, and comparing the results of VIs and drought indices. As mentioned above, meteorological drought indices fail to indicate real drought conditions for terrestrial plants when they are irrigated, and therefore we selected CDs that were mainly covered by grass to study the SIF response to drought. Relationships were obtained and discussed by month (from June to September) according to the adjacent CDs over a six-year period. Although previous studies have shown that the GOME-2 SIF correlates well with ground-based GPP, contrasts and analyses between humid and drought years have rarely been made. Here we examined the seasonal cycle and the consistency of GOME-2 SIF and flux-estimated GPP for both dry and humid years. Finally, we applied a simple model using SIF and NDVI to monitor and assess agricultural drought, and made comparisons with the spatiotemporal pattern of the meteorological drought monitored by drought indices. Figure 2 shows our technical methodology.

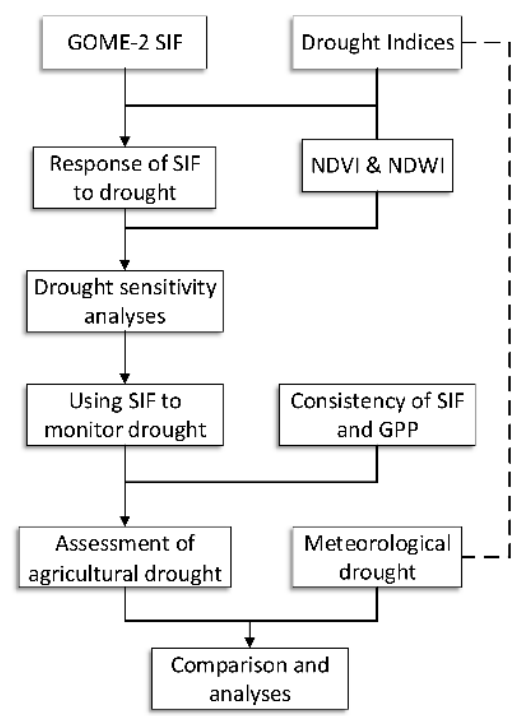

Figure 2. A flow diagram showing the methodology and principles used in this study. 


\section{Results}

\subsection{Response of SIF to Drought}

Figures 3-5 show the correlation between GOME-2 SIF and the multi-time-scale SPI. Two adjacent CDs with similar land cover were grouped together to increase the number of samples used in the regression. We found significant positive correlations $(p<0.05)$ between SIF and all the drought indices for almost every $\mathrm{CD}$ from June to September, but the correlation coefficients varied by month and for different SPI time scales. The correlation coefficients between SIF and SPI-1 were no lower than those between SIF and SPI-2 or SPI-3, but were even higher for CDs 1401/1404 and 3901/3905, indicating that SIF was influenced by the precipitation of the past one to three months. The correlation coefficients between SIF and SPI-1 for CDs 1406/1409 and CDs 2501/2502 were lower. These CDs were near the Mississippi Basin, which has a moist soil [31], and the meteorological drought was eased by ground water. There were no significant correlations between SIF and SPI-2 or SPI-3 in June for CDs 3901/3905, which were located at a higher latitude. However, for CDs at a lower latitude (CDs 1401/1406 and 2501/2502), the correlation coefficients between SIF and SPI-3 in June were higher than in other months. The phenology of plant growth at higher latitudes was later than that for plants at lower latitudes [6]. Thus, SIF responded more significantly to precipitation in April, May, and June, when the grass at lower latitudes started to grow, while grass at higher latitudes was not yet growing. The correlation coefficients between SIF and SPI in September were generally lower than in other months. Although drought impacts vegetation production throughout the growing season [37], the sensitivity of plants to water stress varies according to their phenology [38,39]. Photosynthesis is most intensive during the peak greenness season (July and August), but is weaker in the senescence period (September). Thus SIF is more sensitive to drought in the peak growing months.

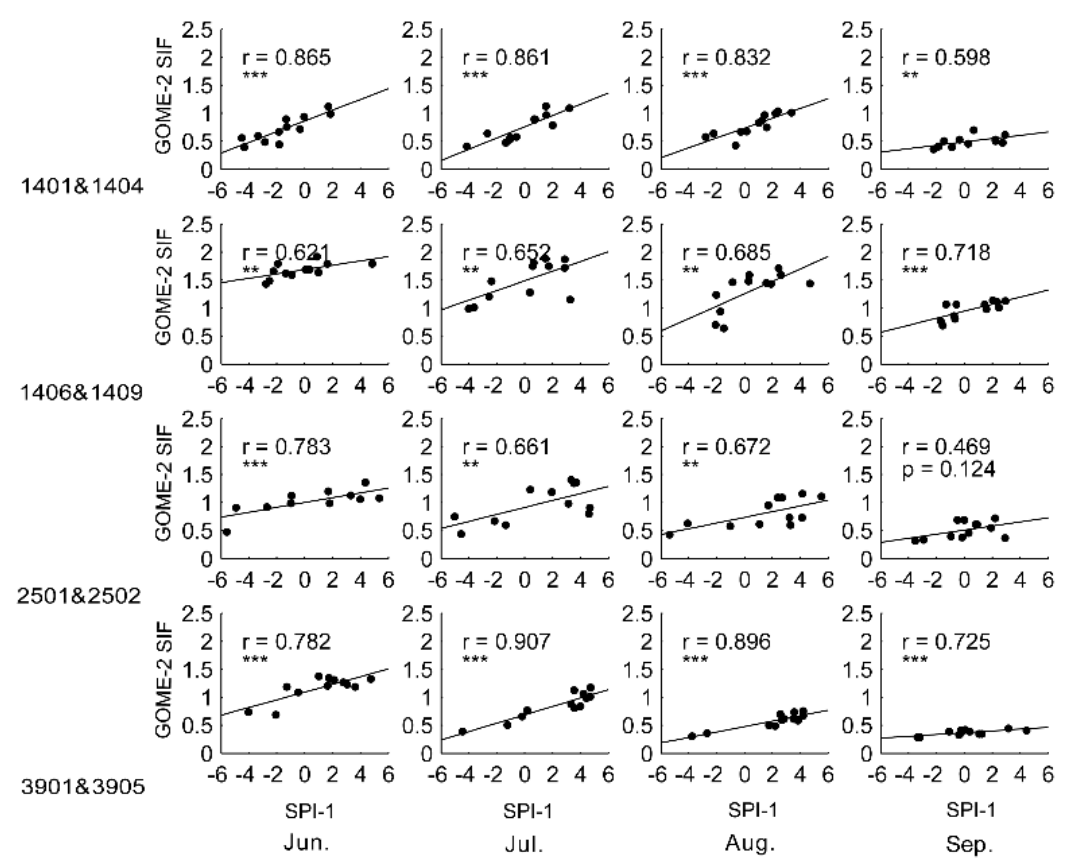

Figure 3. Relationship between the one-month standard precipitation index (SPI) and Global Ozone Monitoring Instrument 2 (GOME-2) solar-induced chlorophyll fluorescence (SIF). The " $\mathrm{r}$ " in the figure represents the correlation coefficient, while "*** and "****" represent the significance levels $p<0.05$ and $p<0.01$, respectively. 


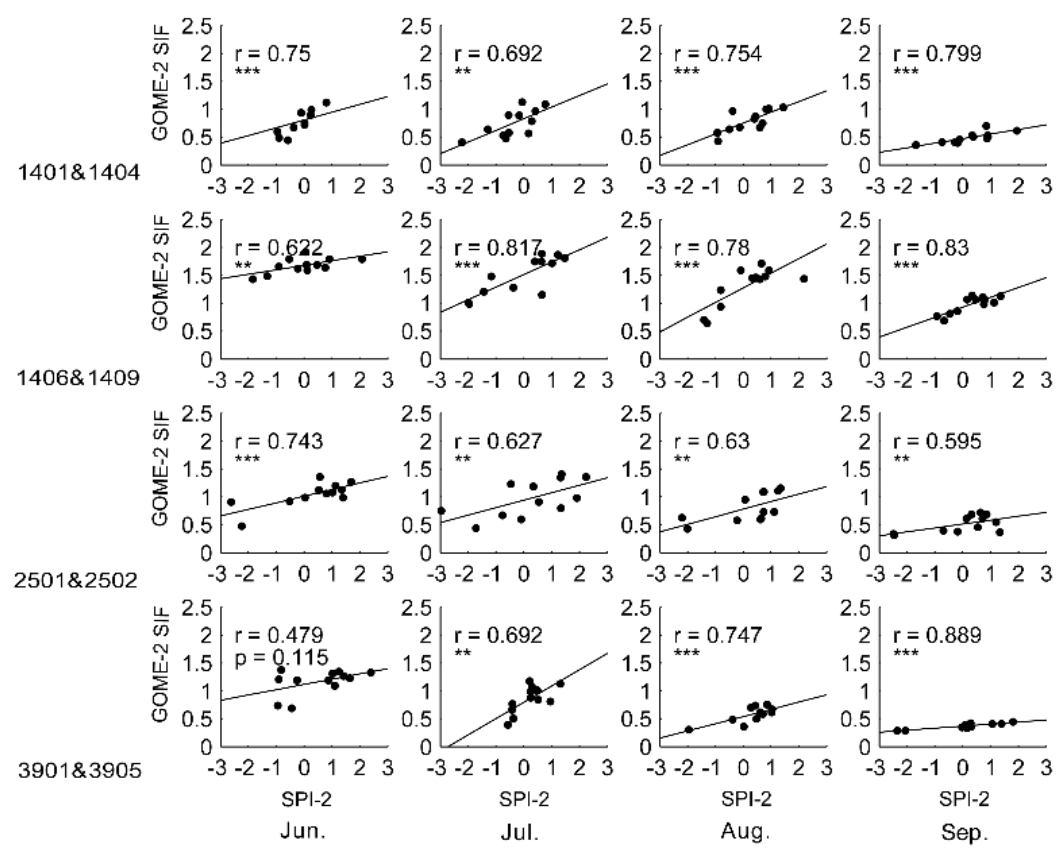

Figure 4. Relationship between the two-month standard precipitation index (SPI) and Global Ozone Monitoring Instrument 2 (GOME-2) solar-induced chlorophyll fluorescence (SIF). The " $\mathrm{r}$ " in the figure represents the correlation coefficient, while "*** and "****" represent the significance levels $p<0.05$ and $p<0.01$, respectively.

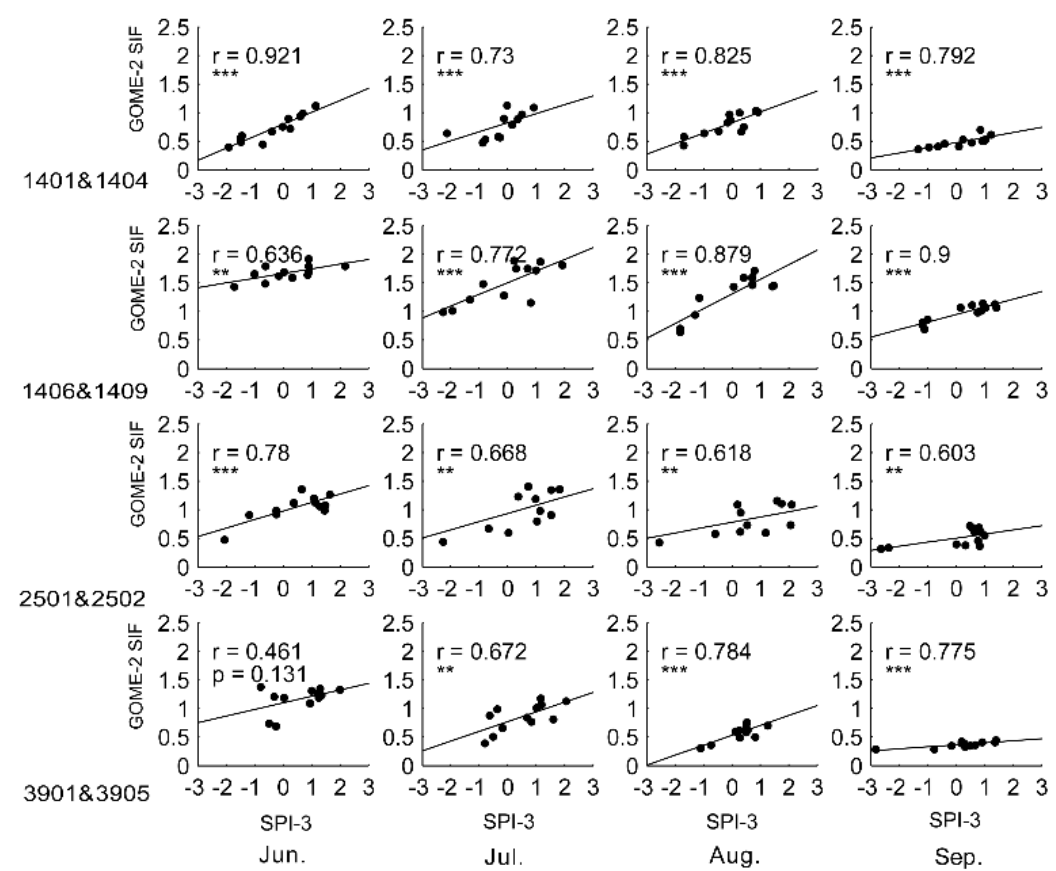

Figure 5. Relationship between the three-month standard precipitation index (SPI) and Global Ozone Monitoring Instrument 2 (GOME-2) solar-induced chlorophyll fluorescence (SIF). The " $r$ " in the figure represents the correlation coefficient, while "***" and "****" represent the significance levels $p<0.05$ and $p<0.01$, respectively.

Figure 6 shows the correlation coefficients of the SPI and SIF, and the NDVI or NDWI during the peak growing season (from June to August). Figure 6 shows that the correlation coefficients of the SPI-1 and SIF are higher than those of the SPI-1 and VIs, while the correlation coefficients between the SPI-3 
and SIF are lower than those between the SPI-1 and NDVI. The correlation coefficients between the SPIs and NDVI or NDWI increased significantly when the time scale of the SPI was expanded, which concurred with a previous study [6], indicating that VIs respond more strongly to precipitation over a longer historical period. For SIF, the correlation coefficients increased slightly as the SPI time scale was expanded in subfigures (a) and (b), while in subfigures (c) and (d), the strongest relationships were found for SPI-2 and SPI-1, respectively. This means that the relationship between SIF and historical precipitation remained relatively stable over the past one to three months, but that SIF responds more strongly to more recent precipitation. It is reasonable to conclude that significant positive relationships were found between GOME-2 SIF and multi-time-scale SPIs.
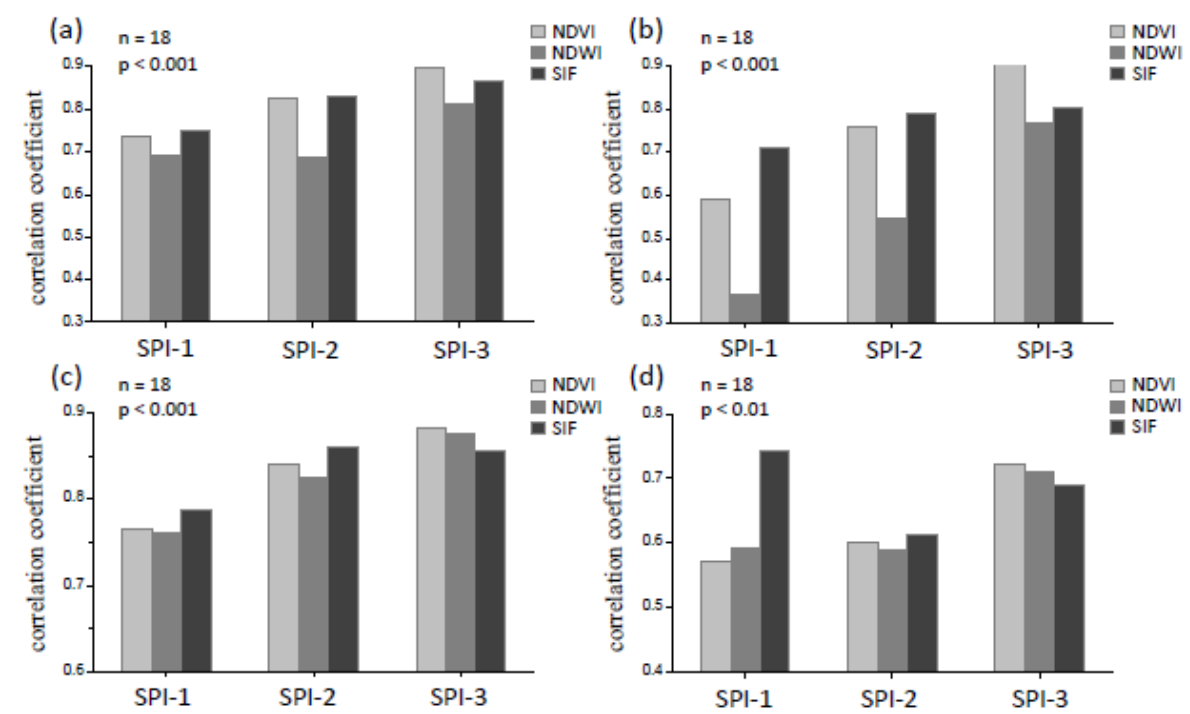

Figure 6. Correlation coefficients of short-term standard precipitation indices (SPIs) and solar-induced chlorophyll fluorescence (SIF), normalized difference vegetation index (NDVI), and the normalized difference water index (NDWI) from June to August. Results for CD 1401, CD1404, CD2501, and CD3901 are indicated by (a-d), respectively. The " $n$ " in the subfigure represents the sample number of the regression analysis while the " $p$ " represents the lowest significance level of the linear relationship between SIF and SPI.

Figure 7 shows the relationship between SIF and PDSI. The PDSI indicates the current drought condition for vegetation considering both heat and water stress. We found a significant positive relationship for all CDs in June, July, and August, while in September the relationship was weaker. Water and heat stress both restrained the photosynthetic rate [40,41]. Briantais et al. [41] found an increase in the minimum level of chlorophyll fluorescence when the heat stress was aggravated, which was assumed to result from an increase in non-photosynthetically-used APAR. Recent ground and aerial-based experiments have shown that SIF tends to decrease under drought stress [42], and the drought-induced reduction of SIF is considered a result of the increase in heat dissipation [43] and a decline in the LUE and APAR [25]. More comprehensively, Ač et al. [44] reported that both water and heat stress lead to a decline in chlorophyll fluorescence. In this study, the positive correlations between GOME-2 SIF and PDSI indicate that plants emit weaker SIF under the combined stress of heat and water.

The main conclusion that can be drawn from the correlations between SIF and the various drought indices is that GOME-2 SIF responds significantly to drought over seasons and years, and positive correlations between SIF and drought indices were found. This provides the basis for the use of satellite-measured SIF to monitor large-scale droughts. 


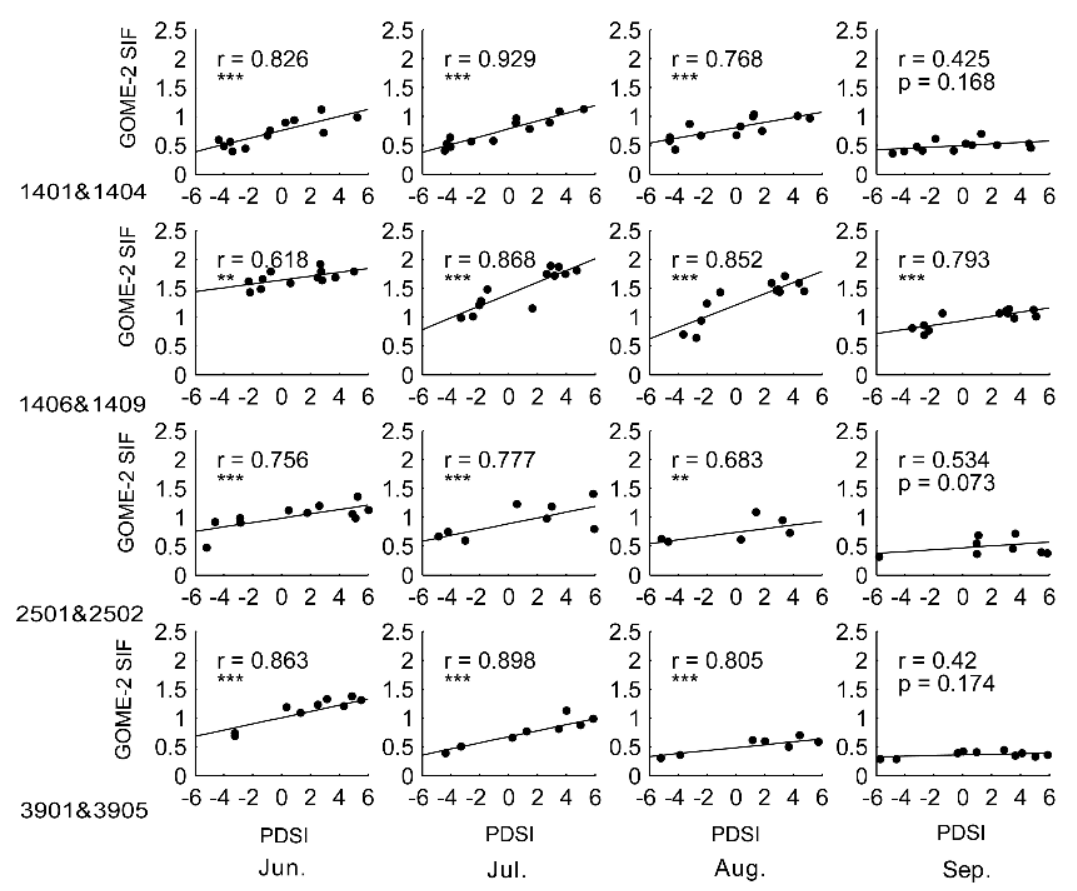

Figure 7. Relationship between the Palmer drought severity index (PDSI) and Global Ozone Monitoring Instrument 2 (GOME-2) solar-induced chlorophyll fluorescence (SIF). The " $\mathrm{r}$ " in the figure represents the correlation coefficient, while "***" and "****" represent the significance levels $p<0.05$ and $p<0.01$, respectively.

\subsection{Consistency of SIF and GPP}

To directly use SIF to assess the impact of drought on GPP, we examined the consistency of flux-estimated GPP and GOME-2 SIF over long periods. Figure 8 shows the inter-annual and seasonal patterns of GOME-2 SIF and GPP. For the four sites, the two variables displayed similar seasonal patterns. For grassland, a significant increase in SIF and GPP occurred in May, but for cropland GPP tended to increase in June, when SIF was already high. The significant difference in the spatial scale, which is $40 \times 40 \mathrm{~km}$ for GOME-2 SIF and dozens of meters for flux measurements, also introduced uncertainties into the comparison of seasonal patterns for GPP and SIF. Although a slight difference was apparent in the seasonal patterns, the GOME-2 SIF was consistent with GPP at seasonal and inter-annual scales.

There was an extreme drought in the central Great Plains in 2012. The seasonal rainfall failed to occur during May to August [45]. We found some anomalies in the patterns of GOME-2 SIF and GPP in 2012. For sites without irrigation, i.e., KFS (Figure 8a), Kon (Figure 8b), and Ne-3 (Figure 8d), the peak values of SIF and GPP in 2012 were significantly lower than those of humid years, taking 2010 as an example. Table 2 shows the statistical results of the decline in the percentage of peak values for SIF and GPP in 2012 compared to 2010. For all three sites, SIF and GPP were reduced by at least $20 \%$ in July, and by 10 to over $40 \%$ in August. A reduction in NPP in 2012 was also found by Guan et al. [27]. when using GOME-2 SIF to estimate crop yield in the adjacent area, with the decline considered to be the result of drought. The 2012 drought reached its peak severity in August and then eased from September onward [45]. A recovery of SIF and GPP in September 2012 can be seen in Figure 8. However, for the irrigated site, $\mathrm{Ne}-1$ (Figure 8c), we found no significant anomalies in the pattern of GPP, although there was an obvious reduction of SIF in July and August. The maize grown at Ne-1 can be regarded as continuous and homogenous [36], but for GOME-2 SIF, the area of a single pixel (approximately as big as $40 \times 40 \mathrm{~km}$ ) is likely to be contaminated with non-irrigated plants such as grass or shrubs. Thus, the influence of the 2012 drought was found in the GOME-2 SIF pattern, but not in the GPP pattern. 


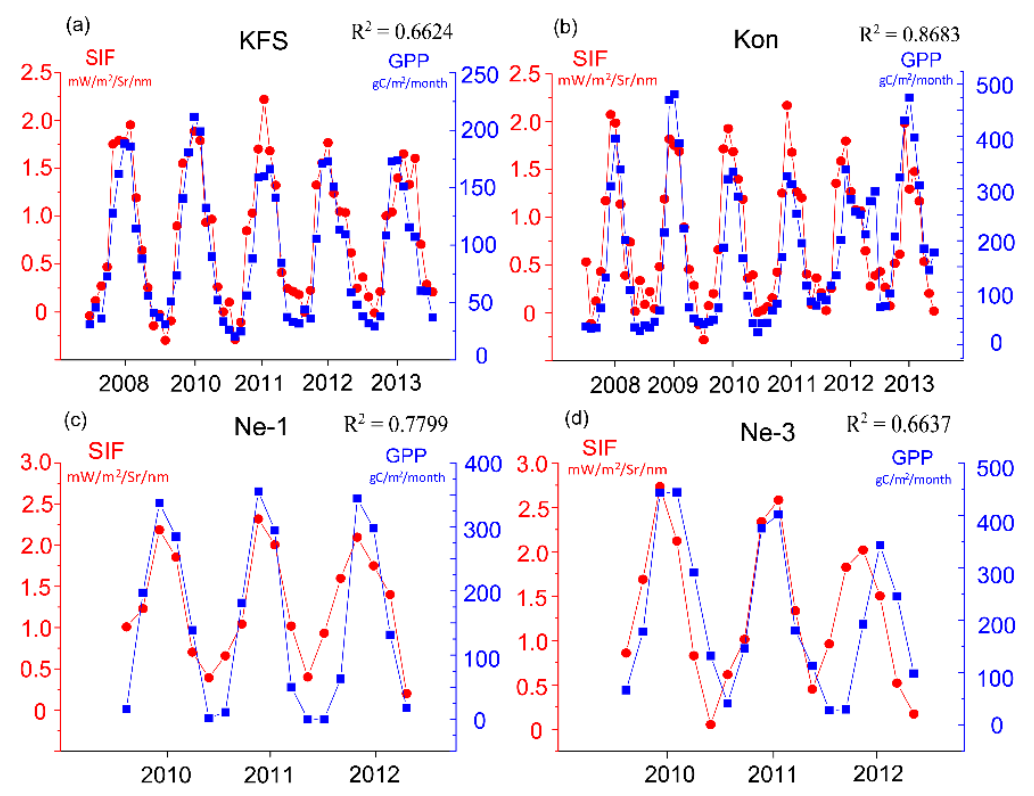

Figure 8. Seasonal patterns of Global Ozone Monitoring Instrument 2 (GOME-2) solar-induced chlorophyll fluorescence (SIF) and flux estimated gross primary production (GPP). Subfigures $(\mathbf{a}, \mathbf{b})$ show the pattern for all 12 months of the year, while subfigures (c,d) show the pattern for six months (from May to October), because flux observations start in May and end in October at Ne-1 and Ne-3.

Figure 8 shows that although the pattern of SIF may differ slightly from that of GPP, GOME-2 SIF remained consistent with the GPP during the growing season for both drought and non-drought years. Thus, it is reasonable to use GOME-2 SIF to assess the impact of drought on vegetation production.

Table 2. Percentage decline in SIF and GPP in July and August of 2012 compared to 2010. The percentage decline (P) of SIF (GPP) was calculated by the formula: $\mathrm{P}=\frac{\mathrm{SIF}_{2010}-\mathrm{SIF}_{2012}}{\mathrm{SIF}_{2010}}$.

\begin{tabular}{ccccc}
\hline \multirow{2}{*}{ Site Name } & \multicolumn{4}{c}{ Percentage Decline Compared to 2010 } \\
\cline { 2 - 5 } & SIF (July) & GPP (July) & SIF (August) & GPP (August) \\
\hline KFS & 29 & 34 & 43 & 41 \\
Kon & 25 & 23 & 16 & 10 \\
Ne-3 & 26 & 57 & 29 & 23 \\
\hline
\end{tabular}

\subsection{Monitoring and Assessing the 2012 Drought}

Figure 9 shows the SPI-3 values of CDs located in the Great Plains from May to October. A large-scale meteorological drought started in June, mainly in the southeastern and western areas of the Great Plains. In July and August, the drought area expanded and was centered in the middle of the Great Plains. In September, although the SPI-3 of some northern CDs remained low, the drought in the southern CDs began to diminish. By October, large-scale drought conditions were no longer experienced over the Great Plains. Figure 9 shows that the drought swept through the Great Plains in the summer of 2012, starting in June, reaching a peak in July and August, and fading away gradually from September to October. A more serious drought occurred in CDs at middle and low latitudes, and both the grassland (western area) and the cropland (eastern area) in the Great Plains received scant precipitation during the summer (see Figure 1 for land-cover information). 

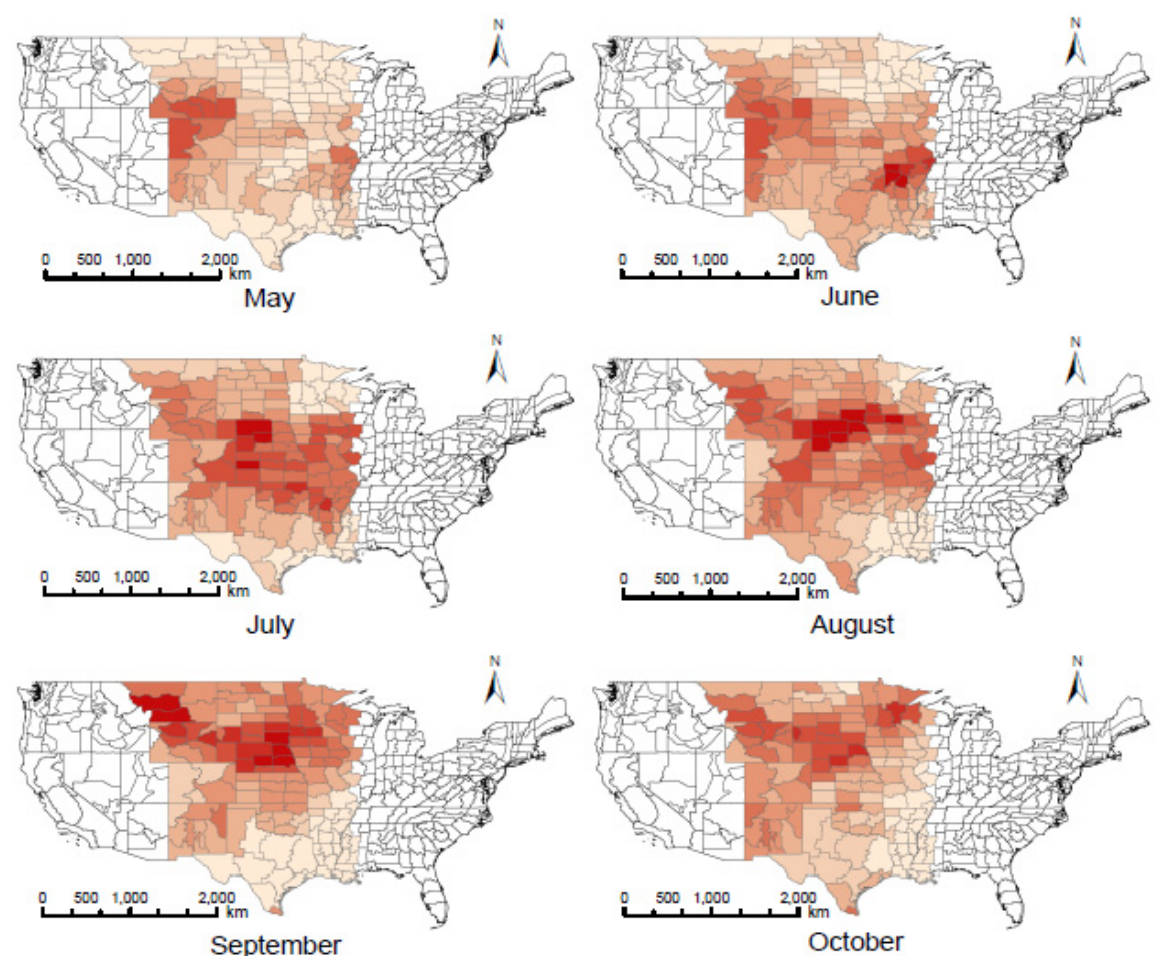

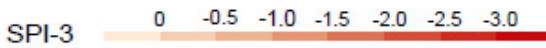

Figure 9. The lack of precipitation over the Great Plains from May to October in 2012. The lower values of the three-month standard precipitation index (SPI-3) (deeper red) indicate less precipitation.

Based on the significant response of SIF to drought and the consistency between SIF and GPP, we employed a simple model using the difference of the SIF in 2012 and the SIF in a historically humid year (here we used 2010) to monitor the plants' responses to this drought, and to make an assessment of the drought-induced reduction of GPP. Figure 10 shows the percentage decline of SIF from May to October in 2012 compared to 2010. The spatial pattern of Figure 10 is similar to that of Figure 9, in that the reduction of SIF was concentrated in the months with the poorest precipitation (from June to September), and the most significant and widespread reduction in SIF occurred in July and August. According to the results given in Section 4.2 and previous studies that considered the relationship between GOME-2 SIF and GPP, the greater reduction of SIF compared to the corresponding historical period was considered to indicate more reduction in the GPP. The production of the Great Plains in 2012 was significantly reduced during the growing season. In May, the reduction occurred mainly in the south, over a very limited area. However, in June a large-scale reduction occurred over the whole western area of the Great Plains, whereas production in the east remained at normal levels. In July and August, a significant reduction occurred in most areas of the Great Plains. The western and middle areas experienced the most severe reduction, while the reduction was relatively smaller in the eastern area. From September to October, the large-scale reduction gradually diminished. Most of the reduction was concentrated in the middle and western areas in June, July, and August. As mentioned in Section 4.1, plants are most sensitive to water stress in the peak growing season. Thus, the impact of drought is most significant in this period. Overall, the SIF not only successfully tracked the evolution of the meteorological drought, but allowed us to assess the drought-induced reduction of GPP as well. 

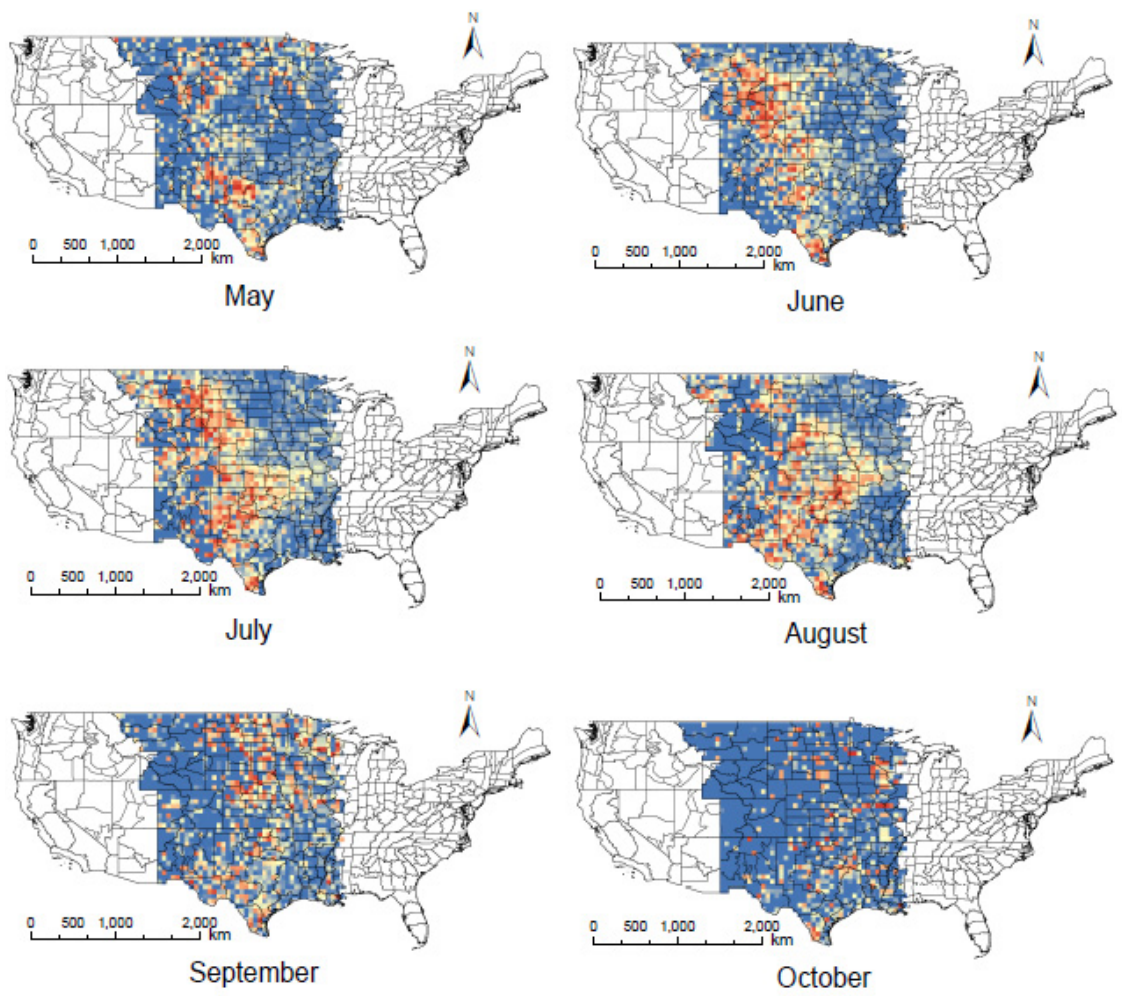

$$
\begin{gathered}
\text { SIF reduction } \\
100 \% \\
0
\end{gathered}
$$

Figure 10. The reduction of solar-induced chlorophyll fluorescence (SIF) from May to October in 2012.

Figure 11 is a map showing the reduction in the NDVI. From May to June, the spatiotemporal pattern of the decline in NDVI values was quite similar to that of SIF, indicating that during this season, the drought-induced reduction of SIF also applied to the NDVI. It has been reported that the drought-induced reduction of SIF is related to the reduction of APAR (or the fraction of absorbed photosynthetic active radiation, FAPAR), to which the NDVI is also sensitive. This may explain the similarity between Figures 10 and 11. However, there are two major distinctions between the two patterns:

- First, Figure 10 is redder than Figure 11, which indicates that SIF declined more significantly during the drought. The saturation effect of the NDVI has been widely discussed (e.g., [46,47]), while SIF and APAR are reported to be better indicators for vegetation production [23]. Asner et al. [46]. indicated that an NDVI-driven NPP model failed to capture differences in vegetation production caused by drought stress at the beginning and end of the dry season because of the NDVI saturation effect. The results in Figures 10 and 11 suggest that SIF might be more appropriate than NDVI to precisely indicate the agricultural drought level.

- Second, the spatiotemporal reduction map for the NDVI was more similar to SPI-3, especially in September and October. Ji and Peters [6] found that the most significant correlation between the NDVI and SPI occurred for the SPI-3, while Figures 3-6 in this study show that SIF was more sensitive to shorter-term SPIs. It has been demonstrated that the 2012 drought in the Great Plains eased in September and October. In addition, the recovery of GPP in these two months (Figure 8) also indicates an easing of the agricultural drought, although this is not obvious in Figure 11.

These two aspects of differences may help illustrate the advantage of SIF over NDVI to indicate agricultural drought, for its timeliness and directness. 

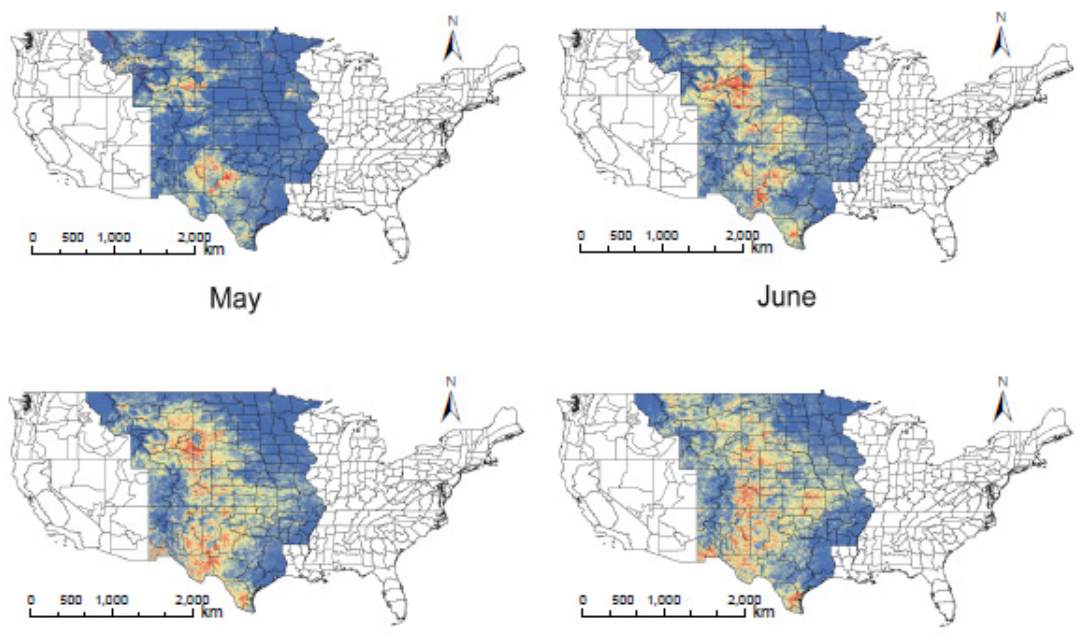

July

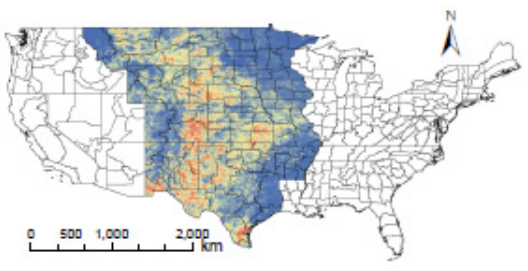

August
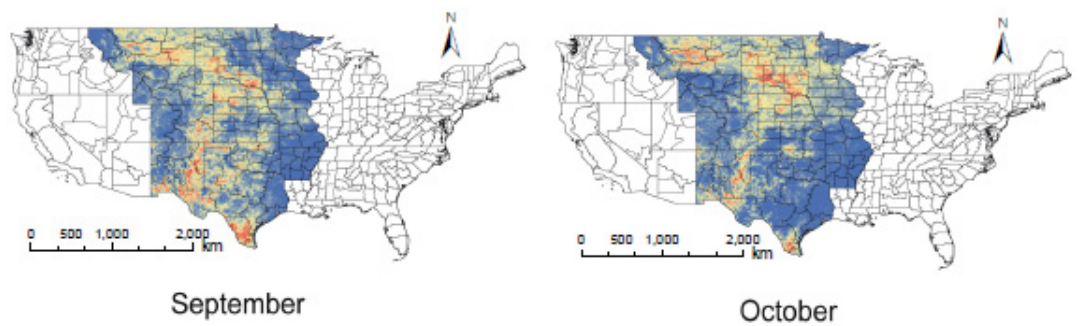

October

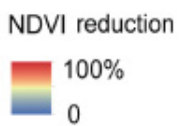

Figure 11. The reduction of the normalized difference vegetation index (NDVI) from May to October in 2012.

\section{Discussions}

\subsection{Drought Sensitivity of SIF and VIs}

The time-lag between reflectance based vegetation and drought indices and the precipitation deficit is significant and has been widely discussed. Although the NDWI was previously found to be more sensitive to drought than the NDVI [13] (a similar conclusion could not be reached in this study), they both fail to indicate rapid changes in drought stress because they have no direct link to photosynthetic functioning beyond their sensitivity to changes in canopy structure and pigment concentration [17]. Alternatively, SIF is directly related to photosynthesis and water stress has been detected by SIF in both ground (e.g., [48,49]) and aerial studies (e.g., [22,31]). Thus the decline of photosynthesis due to drought stress is expected to be reflected by satellite-measured SIF.

The significant correlations between SIF and multi-time-scale SPIs (Figures 3-5) indicate that GOME-2 SIF has good drought sensitivity. Table 3 shows the correlation coefficients between the NDVI and the multi-time-scale SPIs during the peak growing season. For most cases SIF gave higher correlations to SPI-1 and SPI-2 than the NDVI. Thus, regarding the result shown in Figure 6, SIF might be more sensitive to short-term precipitation but less sensitive to long-term precipitation than VIs, because the photosynthetic activity is mainly affected by the current water stress conditions while the green biomass or the canopy absorption of the spectrum reflects the growing status, which is influenced by water conditions all through the growing season. The more significant reduction of SIF (Figure 10) than NDVI (Figure 11) indicates that SIF is more drought-sensitive because SIF reduction results from the reduction of both FAPAR and SIF $_{\text {yield }}$ [30] whereas the NDVI only reflects the FAPAR 
reduction. In addition, for some CDs (e.g., CDs 1406 \& 1409 and CDs 2501 \& 2502) during the peak growing season, the correlation between SIF and the PDSI was more significant than that between SIF and the SPI-1, indicating that SIF might be more sensitive to the combined stress from both high temperatures and scant precipitation than it is to water stress alone. This can be explained by the fact that both precipitation and temperature play critical roles in plant growth and heat-induced drought can lead to further declines in GPP and yield. The sensitivity of SIF to short-term drought stress provides an opportunity to employ SIF to monitor drought at an earlier stage. The similarity of the spatial pattern and temporal variation shown in Figures 9 and 10 also shows that SIF can track the evolutionary process of drought in a timely manner. Thus, satellite-measured SIF is a promising remotely-sensed index for drought monitoring that directly indicates drought-induced restrictions for photosynthesis.

Table 3. Correlation coefficients between SPIs and NDVI during the peak growing season.

\begin{tabular}{llllllllll}
\hline \multirow{2}{*}{$\begin{array}{l}\text { Correlation } \\
\text { Coefficients }\end{array}$} & \multicolumn{3}{c}{ June } & \multicolumn{3}{c}{ July } & \multicolumn{3}{c}{ August } \\
\cline { 2 - 10 } & SPI-1 & SPI-2 & SPI-3 & SPI-1 & SPI-2 & SPI-3 & SPI-1 & SPI-2 & SPI-3 \\
\hline $1401 \& 1404$ & 0.682 & 0.736 & 0.928 & 0.687 & 0.865 & 0.862 & 0.477 & 0.699 & 0.807 \\
$1406 \& 1409$ & 0.690 & 0.710 & 0.695 & 0.805 & 0.888 & 0.867 & 0.450 & 0.814 & 0.898 \\
$2501 \& 2502$ & 0.622 & 0.724 & 0.781 & 0.687 & 0.659 & 0.762 & 0.743 & 0.744 & 0.711 \\
$3901 \& 3905$ & 0.494 & 0.545 & 0.552 & 0.440 & 0.518 & 0.636 & 0.829 & 0.806 & 0.811 \\
\hline
\end{tabular}

\subsection{Difference of the Spatial Pattern for Meteorological and Agricultural Drought}

It is notable that in Figure 10, although serious meteorological drought occurred throughout the Great Plains (Figure 9), there was less reduction in production in the eastern area than in the western and middle areas. The eastern area of the Great Plains is widely covered by irrigated crops and water storage is more abundant [50], and therefore the drought-induced reduction of production was less extensive. Although Guan et al. [27] reported a drought-induced reduction of crop yield in U.S. croplands in 2012, agricultural drought mainly occurred in grassland areas of the western Great Plains. The impact of the drought on the GPP of crops was eased by irrigation and groundwater storage. This indicates that meteorological drought causes more severe ecological damage in arid areas. Food security for humans was ensured, but the situation for wildlife was uncertain. The NDVI also has the potential to indicate agricultural drought, although the reduction of the NDVI in September and October (Figure 11), which was not found for SIF, might be a false interpretation of drought conditions. On the one hand, the ability of the NDVI to respond to short-term precipitation is limited, which may lead to a lag in expressing the recovery of vegetation production. On the other hand, terrestrial plants, especially at higher altitudes, have reached senescence in September and October. Thus, although the NDVI declined significantly, the real agricultural drought, which emphasizes a decline in yield or GPP, may be less serious.

\section{Conclusions}

Remote sensing vegetation indices and meteorological drought indices have been used to monitor drought for decades. Solar-induced chlorophyll fluorescence provides an alternative observation of terrestrial plants from space, and could monitor agricultural drought more quickly and effectively. In this study, we first examined the response of SIF to drought by analyzing the relationships between GOME-2 SIF and several drought indices, including one-, two-, and three-month SPIs, and the PDSI. We found significant positive correlations between GOME-2 SIF and all drought indices, indicating that SIF responds strongly and quickly to drought. SIF was more sensitive to short-term precipitation and less sensitive to long-term precipitation than VIs (NDVI and NDWI). We compared the seasonal and inter-annual patterns of GOME-2 SIF and flux-estimated GPP, and found good consistency between SIF and GPP in both humid and drought years. The SIF and GPP declined synchronously in drought years 
during the peak growing season. Finally, we used a simple SIF-based model to monitor and assess the drought in the Great Plains in the summer of 2012. We found that the SIF-based model successfully tracked the spatial patterns and temporal vibration of SPI-3. We found more severe reduction of plant production in grassland than in cropland areas. SIF declined more significantly than NDVI during the peak growing season. Yet for senescence, during which time the reduction of NDVI still went on, the reduction of SIF was eased.

We examined the response of SIF to drought over long time periods by analyzing GOME-2 SIF and drought indices, and then used SIF to monitor and assess drought. This work highlighted the benefits of using space-borne SIF to monitor and assess drought and better understand the relationship between large-scale drought and its influence on vegetation production. Further research should focus on the development and validation of a more advanced drought monitoring model, considering both meteorological and agricultural factors.

Acknowledgments: The data used in this study were provided by the Goddard Space Flight Center of the National Aeronautics and Space Administration (NASA), the NCDC, and the AmeriFlux website. The KFS and $\mathrm{KON}$ AmeriFlux stations are supported through AmeriFlux core site funding from the U.S. Department of Energy under a sub contract from DE-AC02-05CH1123. This work was supported in part by the National Natural Science Foundation of China under Grant 41501394, the Open Fund of State Key Laboratory of Remote Sensing Science under Grant Y4Y00100KZ, the Chinese Carbon Monitoring Satellite Key Plan for Terrestrial Ecosystem under Grant Y5H0630034, the Direct Youth Foundation of the Institute of Remote Sensing and Digital Earth, Chinese Academy of Sciences (grant No. Y5SJ2000CX), and the China Postdoctoral Science Foundation (grant No. 2014M550871).

Author Contributions: Siheng Wang designed and conducted the experiments, and wrote the whole manuscript; Changping Huang gave constructive suggestions on experiment design and the arrangement of the chapters; Yi Lin, Yi Cen, and Taixia Wu reviewed the manuscript and gave useful advice; Lifu Zhang supervised the research and provided useful suggestions all through the preparation of the manuscript.

Conflicts of Interest: The authors declare no conflict of interest.

\section{References}

1. Easterling, D.R. Climate extremes: Observations, modeling, and impacts. Science 2000, 289, $2068-2074$. [CrossRef] [PubMed]

2. $\quad$ Breshears, D.D.; Cobb, N.S.; Rich, P.M.; Price, K.P.; Allen, C.D.; Balice, R.G.; Romme, W.H.; Kastens, J.H.; Floyd, M.L.; Belnap, J.; et al. Regional vegetation die-off in response to global-change-type drought. Proc. Natl. Acad. Sci. USA 2005, 102, 15144-15148. [CrossRef] [PubMed]

3. Zhao, M.; Running, S.W. Drought-induced reduction in global terrestrial net primary production from 2000 through 2009. Science 2010, 329, 940-943. [CrossRef] [PubMed]

4. Heim, R.R., Jr. A review of twentieth-century drought indices used in the United States. Bull. Am. Meteorol. Soc. 2002, 83, 1149-1165.

5. Wilhite, D.A. Drought as a natural hazard: Concepts and definitions. Drought 2000, 1, 3-18.

6. Ji, L.; Peters, A.J. Assessing vegetation response to drought in the northern great plains using vegetation and drought indices. Remote Sens. Environ. 2003, 87, 85-98. [CrossRef]

7. Palmer, W.C. Meteorological Drought; US Department of Commerce: Weather Bureau Washington, DC, USA, 1965.

8. McKee, T.B.; Doesken, N.J.; Kleist, J. Drought Monitoring with Multiple Time Scales; American Meteorological Society: Boston, MA, USA, 1995.

9. McKee, T.B.; Doesken, N.J.; Kleist, J. The Relationship of Drought Frequency and Duration to Time Scales; American Meteorological Society: Boston, MA, USA, 1993; pp. 179-183.

10. Rhee, J.; Im, J.; Carbone, G.J. Monitoring agricultural drought for arid and humid regions using multi-sensor remote sensing data. Remote Sens. Environ. 2010, 114, 2875-2887. [CrossRef]

11. Gao, B.-C. NDWI-A normalized difference water index for remote sensing of vegetation liquid water from space. Remote Sens. Environ. 1996, 58, 257-266. [CrossRef]

12. Kogan, F.N. Droughts of the late 1980s in the United States as derived from noaa polar-orbiting satellite data. Bull. Am. Meteorol. Soc. 1995, 76, 655-668. [CrossRef] 
13. Gu, Y.; Brown, J.F.; Verdin, J.P.; Wardlow, B. A five-year analysis of MODIS NDVI and NDWI for grassland drought assessment over the central great plains of the United States. Geophys. Res. Lett. 2007, 34. [CrossRef]

14. Di, L.; Rundquist, D.C.; Han, L. Modelling relationships between NDVI and precipitation during vegetative growth cycles. Int. J. Remote Sens. 1994, 15, 2121-2136. [CrossRef]

15. Yang, W.; Yang, L.; Merchant, J. An assessment of AVHRR/NDVI-ecoclimatological relations in Nebraska, USA. Int. J. Remote Sens. 1997, 18, 2161-2180. [CrossRef]

16. Zeng, F.-W.; Collatz, G.; Pinzon, J.; Ivanoff, A. Evaluating and quantifying the climate-driven interannual variability in global inventory modeling and mapping studies (GIMMS) normalized difference vegetation index (NDVI3G) at global scales. Remote Sens. 2013, 5, 3918-3950. [CrossRef]

17. Dobrowski, S.; Pushnik, J.; Zarcotejada, P.; Ustin, S. Simple reflectance indices track heat and water stress-induced changes in steady-state chlorophyll fluorescence at the canopy scale. Remote Sens. Environ. 2005, 97, 403-414. [CrossRef]

18. Joiner, J.; Guanter, L.; Lindstrot, R.; Voigt, M.; Vasilkov, A.P.; Middleton, E.M.; Huemmrich, K.F.; Yoshida, Y.; Frankenberg, C. Global monitoring of terrestrial chlorophyll fluorescence from moderate-spectral-resolution near-infrared satellite measurements: Methodology, simulations, and application to GOME-2. Atmos. Meas. Tech. 2013, 6, 2803-2823. [CrossRef]

19. Köhler, P.; Guanter, L.; Joiner, J. A linear method for the retrieval of sun-induced chlorophyll fluorescence from GOME-2 and SCIAMACHY data. Atmos. Meas. Tech. 2015, 8, 2589-2608. [CrossRef]

20. Joiner, J.; Yoshida, Y.; Vasilkov, A.P.; Yoshida, Y.; Corp, L.A.; Middleton, E.M. First observations of global and seasonal terrestrial chlorophyll fluorescence from space. Biogeosciences 2011, 8, 637-651. [CrossRef]

21. Pérez-Priego, O.; Zarco-Tejada, P.J.; Miller, J.R.; Sepulcre-Cantó, G.; Fereres, E. Detection of water stress in orchard trees with a high-resolution spectrometer through chlorophyll fluorescence in-filling of the O2-A band. Geosci. Remote Sens. IEEE Trans. 2005, 43, 2860-2869. [CrossRef]

22. Zarco-Tejada, P.J.; Berni, J.A.; Suárez, L.; Sepulcre-Cantó, G.; Morales, F.; Miller, J. Imaging chlorophyll fluorescence with an airborne narrow-band multispectral camera for vegetation stress detection. Remote Sens. Environ. 2009, 113, 1262-1275. [CrossRef]

23. Yang, X.; Tang, J.; Mustard, J.F.; Lee, J.-E.; Rossini, M.; Joiner, J.; Munger, J.W.; Kornfeld, A.; Richardson, A.D. Solar-induced chlorophyll fluorescence that correlates with canopy photosynthesis on diurnal and seasonal scales in a temperate deciduous forest. Geophys. Res. Lett. 2015, 42, 2977-2987. [CrossRef]

24. Porcar-Castell, A.; Tyystjarvi, E.; Atherton, J.; van der Tol, C.; Flexas, J.; Pfundel, E.E.; Moreno, J.; Frankenberg, C.; Berry, J.A. Linking chlorophyll a fluorescence to photosynthesis for remote sensing applications: Mechanisms and challenges. J. Exp. Bot. 2014, 65, 4065-4095. [CrossRef] [PubMed]

25. Yoshida, Y.; Joiner, J.; Tucker, C.; Berry, J.; Lee, J.E.; Walker, G.; Reichle, R.; Koster, R.; Lyapustin, A.; Wang, Y. The 2010 russian drought impact on satellite measurements of solar-induced chlorophyll fluorescence: Insights from modeling and comparisons with parameters derived from satellite reflectances. Remote Sens. Environ. 2015, 166, 163-177. [CrossRef]

26. Guanter, L.; Zhang, Y.; Jung, M.; Joiner, J.; Voigt, M.; Berry, J.A.; Frankenberg, C.; Huete, A.R.; Zarco-Tejada, P.; Lee, J.E.; et al. Global and time-resolved monitoring of crop photosynthesis with chlorophyll fluorescence. Proc. Natl. Acad. Sci. USA 2014, 111, E1327-E1333. [CrossRef] [PubMed]

27. Guan, K.; Berry, J.; Zhang, Y.; Joiner, J.; Guanter, L.; Badgley, G.; Lobell, D.B. Improving the monitoring of crop production using spaceborne solar-induced fluorescence. Glob. Chang. Boil. 2015, 10. [CrossRef]

28. Lee, J.E.; Frankenberg, C.; van der Tol, C.; Berry, J.A.; Guanter, L.; Boyce, C.K.; Fisher, J.B.; Morrow, E.; Worden, J.R.; Asefi, S.; et al. Forest production and water stress in Amazonia: Observations from GOSAT chlorophyll fluorescence. Proc. Biol. Sci. 2013, 280. [CrossRef] [PubMed]

29. Zhang, Y.; Guanter, L.; Berry, J.A.; Joiner, J.; van der Tol, C.; Huete, A.; Gitelson, A.; Voigt, M.; Kohler, P. Estimation of vegetation photosynthetic capacity from space-based measurements of chlorophyll fluorescence for terrestrial biosphere models. Glob. Chang. Boil. 2014, 20, 3727-3742. [CrossRef] [PubMed]

30. Sun, Y.; Fu, R.; Dickinson, R.; Joiner, J.; Frankenberg, C.; Gu, L.; Xia, Y.; Fernando, N. Drought onset mechanisms revealed by satellite solar-induced chlorophyll fluorescence: Insights from two contrasting extreme events. J. Geophys. Res. 2015, 120, 2427-2440. [CrossRef]

31. Anderson, M.C.; Hain, C.; Wardlow, B.; Pimstein, A.; Mecikalski, J.R.; Kustas, W.P. Evaluation of drought indices based on thermal remote sensing of evapotranspiration over the continental United States. J. Climate 2011, 24, 2025-2044. [CrossRef] 
32. Joiner, J.; Yoshida, Y.; Vasilkov, A.P.; Schaefer, K.; Jung, M.; Guanter, L.; Zhang, Y.; Garrity, S.; Middleton, E.M.; Huemmrich, K.F.; et al. The seasonal cycle of satellite chlorophyll fluorescence observations and its relationship to vegetation phenology and ecosystem atmosphere carbon exchange. Remote Sens. Environ. 2014, 152, 375-391. [CrossRef]

33. Logan, K.E.; Brunsell, N.A. Influence of drought on growing season carbon and water cycling with changing land cover. Agric. Forest Meteorol. 2015, 213, 217-225. [CrossRef]

34. Brunsell, N.; Nippert, J.; Buck, T. Impacts of seasonality and surface heterogeneity on water-use efficiency in mesic grasslands. Ecohydrology 2014, 7, 1223-1233. [CrossRef]

35. Wagle, P.; Xiao, X.; Suyker, A.E. Estimation and analysis of gross primary production of soybean under various management practices and drought conditions. ISPRS J. Photogramm. Remote Sens. 2015, 99, 70-83. [CrossRef]

36. Suyker, A.E.; Verma, S.B.; Burba, G.G.; Arkebauer, T.J.; Walters, D.T.; Hubbard, K.G. Growing season carbon dioxide exchange in irrigated and rainfed maize. Agric. For. Meteorol. 2004, 124, 1-13. [CrossRef]

37. Kramer, P.J.; Boyer, J.S. Water Relations of Plants and Soils; Academic press: Cambridge, MA, USA, 1995.

38. Teare, I.D.; Peet, M.M. Crop-Water Relations; John Wiley \& Sons: New York, NY, USA, 1983.

39. Ginestar, C.; Castel, J. Responses of young clementine citrus trees to water stress during different phenological periods. J. Hortic. Sci. 1996, 71, 551-560.

40. Souza, R.P.; Machado, E.C.; Silva, J.A.B.; Lagôa, A.M.M.A.; Silveira, J.A.G. Photosynthetic gas exchange, chlorophyll fluorescence and some associated metabolic changes in cowpea (Vigna unguiculata) during water stress and recovery. Environ. Exp. Bot. 2004, 51, 45-56. [CrossRef]

41. Briantais, J.M.; Dacosta, J.; Goulas, Y.; Ducruet, J.M.; Moya, I. Heat stress induces in leaves an increase of the minimum level of chlorophyll fluorescence, Fo: A time-resolved analysis. Photosynth. Res. 1996, 48, 189-196. [CrossRef] [PubMed]

42. Panigada, C.; Rossini, M.; Meroni, M.; Cilia, C.; Busetto, L.; Amaducci, S.; Boschetti, M.; Cogliati, S.; Picchi, V.; Pinto, F.; et al. Fluorescence, PRI and canopy temperature for water stress detection in cereal crops. Int. J. Appl. Earth Obs. Geoinform. 2014, 30, 167-178. [CrossRef]

43. Meroni, M.; Rossini, M.; Guanter, L.; Alonso, L.; Rascher, U.; Colombo, R.; Moreno, J. Remote sensing of solar-induced chlorophyll fluorescence: Review of methods and applications. Remote Sens. Environ. 2009, 113, 2037-2051. [CrossRef]

44. Ač, A.; Malenovský, Z.; Olejníčková, J.; Gallé, A.; Rascher, U.; Mohammed, G. Meta-analysis assessing potential of steady-state chlorophyll fluorescence for remote sensing detection of plant water, temperature and nitrogen stress. Remote Sens. Environ. 2015, 168, 420-436. [CrossRef]

45. Hoerling, M.; Eischeid, J.; Kumar, A.; Leung, R.; Mariotti, A.; Mo, K.; Schubert, S.; Seager, R. Causes and predictability of the 2012 great plains drought. Bull. Am. Meteorol. Soc. 2014, 95, 269-282. [CrossRef]

46. Asner, G.P.; Nepstad, D.; Cardinot, G.; Ray, D. Drought stress and carbon uptake in an amazon forest measured with spaceborne imaging spectroscopy. Proc. Natl. Acad. Sci. USA 2004, 101, 6039-6044. [CrossRef] [PubMed]

47. Gu, Y.; Wylie, B.K.; Howard, D.M.; Phuyal, K.P.; Ji, L. NDVI saturation adjustment: A new approach for improving cropland performance estimates in the greater platte river basin, USA. Ecol. Indic. 2013, 30, 1-6. [CrossRef]

48. Daumard, F.; Champagne, S.; Fournier, A.; Goulas, Y.; Ounis, A.; Hanocq, J.-F.; Moya, I. A field platform for continuous measurement of canopy fluorescence. Geosci. Remote Sens. IEEE Trans. 2010, 48, 3358-3368. [CrossRef]

49. Middleton, E.M.; Huemmrich, K.F.; Cheng, Y.-B.; Margolis, H.A. Chapter 12. Spectral bioindicators of photosynthetic efficiency and vegetation stress. In Hyperspectral Remote Sensing of Vegetation; CRC Press: Boca Raton, FL, USA, 2011; pp. 265-288.

50. DeAngelis, A.; Dominguez, F.; Fan, Y.; Robock, A.; Kustu, M.D.; Robinson, D. Evidence of enhanced precipitation due to irrigation over the great plains of the United States. J. Geophys. Res. 2010, 115. [CrossRef]

(C) 2016 by the authors; licensee MDPI, Basel, Switzerland. This article is an open access article distributed under the terms and conditions of the Creative Commons by Attribution (CC-BY) license (http:/ / creativecommons.org/licenses/by/4.0/). 